\title{
Digitaaliset ihmistieteet kirjallisuudentutkimuksessa
}

Viola Parente-Čapková 
igitaalisuudesta puhutaan kaikkialla, nykyään myös kirjalliD suudentutkijoiden keskuudessa, kuten käy ilmi Hanna-Riikka Roineen ja Laura Piipon toimittamasta Avaimen tämän vuoden teemanumerosta. Digitaalisuuteen liittyvät käsitteet ja ilmaisut kuuluvat monien kirjallisuudentutkijoiden sanastoon. Vai voiko todella puhua monista? Digitaalisten ihmistieteiden konferensseja hallitsevat useimmiten muut ihmistieteiden alat kuin kirjallisuudentutkimus. "Kulttuurisesti ja yhteiskunnallisesti ladattu" digitaalisuus-käsite (Suominen \& Sivula 2016, 97) herättää edelleen epäilyksiä, vaikkei yksikään kirjallisuudentutkija tule nykyään toimeen ilman tietokonetta ja internettiä. Tutkijuus muuttuu koko ajan digitaalisemmaksi: vaikkei tutkisi digitaalisia aineistoja tai ilmiöitä eikä käyttäisi digitaalisia menetelmiä, tapahtuu tutkimukseen liittyvä tiedonhaku, tutkimuksen kirjoittaminen ja esittäminen, sen julkaisuprosessi sekä tutkijoiden vuorovaikutus enenevässä määrin digitalisaation avittamana, pandemian aikana entistä korostuneemmin. Tässä suhteessa tutkijuutta voi ajatella toimijuutena digitaalisen ympäristöllisyyden -käsitteen (environmentality) avulla. Hanna-Riikka Roineen ja Laura Piipon $(2021,7)$ mukaan käsitteellä tarkoitetaan sekä "ihmiskokemuksen uppoutuneisuutta digitaalisen teknologian tuottamiin ja muovaamiin ympäristöihin että tämän uppoutuneisuuden synnyttämiä laajempia yhteiskunnallisia vaikutuksia, jotka heijastuvat myös lukemisen ja kirjoittamisen sosiomateriaalisiin ja institutionaalisiin ulottuvuuksiin".

Digitaalisuuteen kytkeytyvä kirjallisuudentutkimus voidaan lukea laajemmin digitaalisiin ihmistieteisiin, jotka ovat "vielä muotoutuva tutkimusperinne, jossa korostuvat informaatio- ja kommunikaatioteknologiat" (Tolonen 2017, 11). Kirjallisuudentutkimuksessa digitaalisuus voidaankin ymmärtää monella tavalla: se voi olla sekä kohde että keino, väline tai menetelmä. Digitaalisiin menetelmiin kuuluvat esimerkiksi laskennallisten menetelmien sekä analysointi- ja visualisointimenetelmien käyttö: aineistona ovat usein tietokantoihin kerätyt, digitoidut tai syntyjään digitaaliset aineistot tai metadatan eri muodot. ${ }^{1}$ Digitaalisuus tutkimuksen kohteena voi tarkoittaa syntyjään digitaalisen eli elektronisen, usein kokeellisen kirjallisuuden tutkimusta, digitaalisuuteen liittyvien esineiden, teknologioiden ja alustojen tutkimista sekä "teknologian, kirjallisuuden ja ihmistoimijuuden yhteenkietoutuneisuutta digitaalisissa ympäristöissä" (Roine \& Piippo 2021, 8). Se voi tarkoittaa myös metapohdintaa kirjallisuuden ja kirjallisuudentutkimuksen lähtökohdista (esim. Hayles 2008), digitaalisuuden vaikutuksesta kirjallisuuteen sekä aiheeseen liittyviä epistemologisia ja eettisiä kysymyksiä.

Kirjallisuudentutkimukseen pätee Mikko Tolosen (2017, 11) digitaalisia ihmistieteitä koskeva näkemys, jonka mukaan kyseessä on humanistisen tutkimuksen muutos ja uudistuminen pikemminkin kuin uuden, digitaalisen tieteenalan syntyminen. Vaikka jotkut ovat puhuneet digitaalisen humanismin 
yhteydessä uudesta tieteen paradigmasta (Elo 2006, 12), toiset ovat lähestyneet tällaista näkemystä varovaisemmin (Tolonen 2016; Tolonen \& Lahti 2018, 236).

Kirjallisuudentutkimuksen digitaalisuutta voidaan kartoittaa Roman Jakobsonin tunnetun kommunikaatiotilanteen skeeman avulla, vaikka digitaaliset ympäristöt samalla kutsuvat myös skeeman kyseenalaistamiseen. Skeeman kaikkia elementtejä ja niiden välisiä rajoja voidaan ajatella uudelleen: (kirjallisen) viestin lähettäjää eli tekijää, itse viestiä eli kirjallista tekstiä, vastaanottajaa eli lukijaa (tai ehkä paremminkin käyttäjää), kontaktia eli mediumia, koodia eli kieltä ja kontekstia. Tekstin ja kontekstin välistä rajaa sekä tekstienvälisyyttä tulee pohtia digitalisaation yhteydessä uudelleen, koska tekstin ja sitä ympäröivien tekstien erottelua voi kyseenalaistaa uusin periaattein. Kati Launis $(2018,17)$ on korostanut, että kenttää on hallinnut kirjallisen viestin eli teoksen tutkiminen; viime aikoina ovat kuitenkin nousseet tekijyyden ja lukijuuden tutkimus sekä erilaisten (nykyisten ja historiallisten) toimijuuksien ja kirjallisuusinstituutioiden sekä kirjallisen vastaanoton tutkimus (Kuusela 2015; Parente-Čapková 2017; Launis et al. 2018; Roine \& Piippo 2021, 17-21). Jotkut kulttuurintutkimuksellisesti ja sosiologisesti suuntautuneet tutkimukset ovat tarkastelleet kirjallisen elämän digitalisaatiota ja digitaalisuutta Pierre Bourdieun kirjallisen kentän teorian avulla kirjallisuuden levikin ja saavutettavuuden yhteydessä (esim. Sanz 2017). Inhimillisen ja ei-inhimillisen suhdetta, verkostoja ja toimijuuksia on tarkasteltu digitaalisen posthumanismin puitteissa (esim. Hall 2016).

\section{Digitaalinen käänne?}

Kun puhutaan "digitaalisesta käänteestä" kirjallisuudentutkimuksesssa, on hyvä pohtia, mikä on täysin uutta ja mikä taas vähemmän uutta (ks. esim. Underwood 2017). Uusia ovat epäilemättä nykyiset digitaaliset ympäristöt sanan laajassa mielessä, kun taas moni nykykeskustelun elementti muistuttaa aikaisempia debatteja. Kuten Roine ja Piippo $(2021,22)$ sekä Tolonen korostavat, analogisen ja digitaalisen vastakkainasettelu ei ole enää hedelmällistä. "Hyvän digitaalisen humanismin tutkimuksen tunnistaa siitä, että se tietoisesti häivyttää vanhanaikaista laadullinen/tilastollinen -erottelua merkityksettömänä taka-alalle". (Tolonen 2017, 16.) Samaa voi sanoa hyvästä digitaalisesta kirjallisuudentutkimuksesta. Laskennallisuus herättää kuitenkin joissakin kirjallisuudentutkijoissa edelleen negatiivisia tunteita. Laskennallisia menetelmiä on kirjallisuudentutkimuksessa käytetty jo kauan erityisesti tyylin analyysissa (ks. esim. Doležel \& Bailey 1969), ja aiemminkin niitä on pyritty liittämään teosten tulkintaan (esim. Pynsent 1973). Laskennallisuuden kriitikot ovat olleet usein sitä mieltä, että digitaalisten menetelmien avulla saadaan vain aikaiseksi nopeammin ja tehokkaammin se, mikä olisi muuten jouduttu tekemään manuaalisesti. 
Digitaalisten ihmistieteiden pääajatus vähintään alan tutkimuksen "toisesta aallosta" tai vaiheesta lähtien ei kuitenkaan ole ollut datan keräämisessä ja pelkässä laskennallisuudessa vaan laadullisissa lähestymistavoissa ja tulkinnoissa sekä menetelmiä koskevissa pohdinnoissa (Berry 2012, 3).

Tutkimuksen päämääränä ovat uudet näkökulmat, mahdollisuus hahmottaa kohdetta uudella tavalla ja tarjota uudentyyppistä todistusaineistoa (esim. Hoover 2016). Näin on ollut esimerkiksi kriittisten editioiden ja erilaisten konkordanssien tekemisessä. Aikaisemmin ne laadittiin manuaalisesti, toisen maailmansodan jälkeen tietokoneiden avulla. Tämän tyyppinen digitaalisuus kirjallisuudentutkimuksessa voidaan jäljittää digitaalisten ihmistieteiden "alkuperäismyyttiin" (ks. esim. Jones 2016) eli vuoteen 1949, jolloin italialainen jesuiittatutkija Roberto Busa sai IBM-yhtiöltä teknisen ja taloudellisen tuen Tuomas Akvinolaisen teosten laajaa konkordanssia varten. Busa jatkoi tietoteknologian kehitystyötään seuraavien vuosikymmenten aikana, tavoitteenaan digitoida Tuomas Akvinolaisen kirjoitukset laajaa tutkimuskäyttöä varten (esim. Haverinen \& Suominen 2015). Nykyaikaiset digitaaliset kriittiset editiot (Suomessa esim. SKS:n projektit, kuten Edith ja Avoin Kalevala) ovat paljon enemmän kuin digitaaliseen muotoon ja avoimeen verkkoon siirrettyjä painettuja kirjoja: niiden tarkoitus on myös mahdollistaa "erilaisia vaihtoehtoisia tapoja tutkia kirjallisuutta". ${ }^{3}$

Kriittiset editiot laaditaan yleensä kirjallisuuden klassikoista. Joidenkin editioiden yhteydessä - parhaana esimerkkinä Shakespeare - on digitaalisia menetelmiä käytetty myös tekijyyden jäljittämiseen (authorship attribution, ks. esim. Jiménez 2021). Kyse on tällöin stylometry- tai stylometrics-nimisestä alasta, joka on kiinnostunut tyylin tutkimuksesta laajemmin muissakin kuin kirjallisissa diskursseissa, rekistereissä ja lajeissa. ${ }^{4}$ Suuntaukselle on tyypillistä tieteidenvälisyys, koska sen toteuttamat projektit vaativat useamman oppialan - vähintään kirjallisuudentutkimuksen, lingvistiikan, retoriikan, kulttuurihistorian ja historian - yhteistyötä. Sama pätee digitaaliseen narratologiaan, tekstikritiikkiin ja geneettiseen kritiikkiin (ks. esim. Katajamäki 2021). Kirjallisuudentutkijoiden ja kielitieteilijöiden yhteistyöllä on digitaalisissa ihmistieteissä suuri potentiaali, onhan aate- ja kirjallisuushistoria tietyssä mielessä kielihistoriaa, jossa aatteita on rakennettu ja ilmaistu. Tätä historiaa voi nyt tutkia uudella tavalla digitaalisten menetelmien ansiosta (esim. Hancher 2016). Kirjallisuudentutkijoiden ja kielitieteilijöiden yhteistyö konkretisoituu esimerkiksi korpuslingvistisissä tutkimuksissa, joiden aineistona toimivat kirjalliset tekstit. Tällainen ylirajaisuus on sekä digitaalisille ihmistieteille että digitaaliselle kirjallisuudentutkimukselle tyypillistä. Digitaalinen kirjallisuudentutkimus on ylirajaista, tieteidenvälistä (vrt. aiemmin mainittujen oppialojen lisäksi myös sosiologia, posthumanismi tai käännöstiede) ja usein myös kansainvälistä ja transnationaalista digitaalisen kirjallisuuden tapaan (ks. Parente-Čapková 2017; Vairinen 2021). 
Digitaalisuutta kirjallisuudentutkimuksessa voidaan tarkastella kirjallisuudentutkimuksen perinteisen kolmijaon - teorian, analyysin ja historian - avulla, vaikka tällaiset rajanvedot ovat vain veteen piirrettyjä viivoja. Tämä rajojen häilyvyys korostuu monia tutkijoita inspiroineissa, mutta myös ankaran arvostelun kohteiksi joutuneissa Franco Morettin menetelmissä, jotka pohjaavat kirjallisuushistoriallisiin projekteihin. Muun muassa strukturalismin innoittamana Moretti etsi suurissa aineistoissa ilmeneviä rakenteita ja tavoitteli kirjallisen systeemin syvempää ymmärtämistä. Hän tutki eurooppalaisen romaanin historiaa ja hyödynsi tietokoneavusteisia menetelmiä ja visualisointeja, aluksi varsinkin karttoja, kirjallisuutta ja maantiedettä yhdistävässä teoksessaan Atlas of the European Novel, 1800-1900 (1998). Vuonna 2000 Moretti osallistui keskusteluun maailmankirjallisuus-termistä. Hän arvosteli sitä miten termillä oli pitkään viitattu pieneen joukkoon länsimaisia teoksia, joita länsimaisessa akatemiassa "lähiluettiin" uuskriittisen close reading -menetelmän avulla. Psykologi Colin Martindalen ja sosiologi Immanuel Wallersteinin inspiroimana (Ascari, 2014) Moretti ehdotti, että luettaisiin "kaukaa", enemmän ja laajemmin, minkä juuri digitaaliset menetelmät mahdollistaisivat. Menetelmänsä nimeksi hän kehitti käsitteen kaukolukeminen tai etälukeminen (distant reading; ks. Moretti 2013). Moretti $(2005,9,30)$ korosti, että laskennallinen tutkimus tarjoaa vain dataa, johon tutkijan - tai tutkijatiimin - täytyy lisätä tulkinta. Kaukolukemisen ja laajan datan avulla piti saavuttaa uusi katse kirjallisuushistoriaan, voittaa siihen sisäänrakennettu (metodologinen) nationalismi sekä kumota erilaiset "myytit", jotka "matkasivat" kirjallisuudenhistoriasta toiseen ilman, että kukaan tarkisti niitä (esim. jonkun kirjallisen lajin vallitsevuus jonakin tiettynä aikakautena). Laskennallisten menetelmien avulla oli mahdollista kartoittaa paljon luotettavammin esimerkiksi romaanin levikkiä eri aikoina tai nähdä, mitä lajeja julkaistiin tai myytiin eniten minäkin aikana (Moretti 2005).

Morettin ja Matthew Jockersin vuonna 2010 perustamassa Stanford Literary Labissa on kokeiltu erilaisia digitaalisia menetelmiä, kuten erityyppistä tietokoneavusteista tekstianalyysia ja verkostoteoriaa hyödyntävää juonen analyysia. Kaukolukeminen laajeni tarkoittamaan myös tietokoneavusteisia analyyseja. Morettin kollega Jockers (2013) on lanseerannut kaukolukemista yleisemmän makroanalyysi-termin (macroanalysis) vastakohtana mikroanalyysille. Jockersin $(2013,17)$ mukaan makroanalyyttinen menetelmä ei pelkästään mahdollista laajojen aineistojen käsittelyä, vaan myös paljastaa tekstistä seikkoja, joita ei voi lukea esiin mikroanalyysin avulla.

Moni digitaalisista menetelmistä kiinnostunut humanisti on halunnut löytää "kultaisen keskitien" makro- ja mikrotasojen välistä. Useat ovat korostaneet, että samoin kuin määrällinen ja laadullinen, myös kaukolukeminen ja lähilukeminen eivät ole vastakohtia (esim. Hoover 2016; Bode 2018, 19; ks. myös Pettersson 2016). Paul Saint-Amour (2019) on kutsunut keskitien ideaa 
meso-analyysiksi. Saint-Amour kirjoittaa tavoista, joilla ihmistieteet voidaan ymmärtää tyypillisiksi keskitien oppialoiksi ("medial discipline par excellence"). Jokaisen tutkijan täytyy löytää tämä meso-taso itse, olettamatta "helppoa skaalattavuutta mikrosta meson kautta makroon tai päinvastoin" (mt.). Erilaisia meso-analyysin muotoja on kokeiltu tutkimuksissa, joissa tietokoneavusteinen aineistojen ja metadatan haku ja seulonta yhtyvät kontekstualisoivaan otteeseen ja välillä jopa tapaustutkimukselliseen lähilukuun (ks. Parente-Čapková 2021). ${ }^{5}$ Tällaisista menetelmistä on tullut monelle tutkijalle ja projektille itsestäänselvyys käytännön työssä, samoin kuin moni viittaa vastaavissa tapauksissa mixed methods -menetelmiin.

\section{Digitaalisen kirjallisuudentutkimuksen eettisiä kysymyksiä}

Kaukolukemista sekä laajemmin digitaalisten ihmistieteiden menetelmiä on arvosteltu myös jälkikoloniaalisista sekä sukupuolentutkimuksen lähtökohdista. Gayatri Chakravorty Spivak (2003, 107-108) on ihmetellyt tapaa, jolla Moretti kohtelee paikallisia kirjallisuudentutkijoita "natiiveina informantteina". Jonathan Arac (2002) on kritisoinut alun perin italiankielisen Morettin ajatusten "englanninkielistä imperialismia" ja hegemoniaa eli "anglo-globalismia". Jenny Bergenmar ja Katariina Leppänen (2017) ovat tuoneet esiin, miten Morettin julistama globaalinen ja transnationaalinen ote (samoin kuin Jockersin makroanalyysi) sivuuttaa sekä maailman monikielisyyden että sukupuolen. Digitaalisia ihmistieteitä on arvosteltu "valkoisuudesta" (esim. McPherson 2012) ja siitä, miten kirjastojen, arkistojen ja muisti-instituutioiden digitointistrategiat ovat marginalisoineet ei-valkoisia sekä muita aineistoja, jotka eivät kuulu valtavirtaan esimerkiksi sukupuolen perusteella (esim. Sanz 2013; Wernimont 2013; Bergenmar \& Golub 20206). Katherine Bode $(2018,25)$ on kritisoinut morettilaista väitettä kirjallisen datan "puhtaudesta" ja "objektiivisuudesta" sekä näkemystä että se edeltäisi tulkintaa. Toisaalta Bode edustaa tutkijoita, jotka lähtevät morettilaisten menetelmien kritiikistä, mutta tarjoavat monipuolisia tapoja kehittää datarikasteista kirjallisuushistoriaa (data rich literary history) sekä ottavat osaa kirjallisuudentutkimuksen digitaalisuutta koskeviin teoreettismetodologisiin debatteihin. ${ }^{7}$

Bode on ottanut kantaa laajaan keskusteluun kirjallisuudentutkimuksen digitaalisuuteen liittyvistä eettisistä kysymyksistä. Digitaalisuus ja verkossa julkaiseminen tarkoittavat monelle sitä, että tutkimuksen pitäisi olla vapaasti saatavissa avoimina verkkoversioina. Avoin tiede, mukaan lukien avoin data, on avainsana monelle digitaaliselle humanistille, ja se on keskeinen myös akateemisessa sekä muussa digitaalisuutta hyödyntävässä ja digitaalisuutta koskevassa opetuksessa. ${ }^{8}$ Eettiset kysymykset liittyvät digitaalisuuden ja digitalisaation kaikkiin osa-alueisiin, ympäristöystävällisyys mukaan luettuna (esim. Kim \& Stommel 2018). Joihinkin eettisiin kysymyksiin on jo tarkkoja vastauksia 
sääntöjen muodossa, mutta moniin kysymyksiin apua ei löydy. Päävastuu on aina tutkijalla tai tutkijatiimillä, joka joutuu pohtimaan ja ratkaisemaan aiheeseensa ja tapaustutkimukseensa liittyviä eettisiä dilemmoja. Etiikkaan liittyy myös periaate, jonka mukaan digitaalisuudesta ei saa tulla fetissi ja päämäärä (Parente-Čapková 2017; Launis 2018). Enemmän se toimii oivallisena työkaluna tietyntyyppiseen tutkimukseen sekä keinona kysyä uusia tutkimuskysymyksiä ja pohtia digitaalisten aineistojen, tutkimusmenetelmien sekä tutkimuskysymysten välisiä yhteyksiä. ${ }^{9}$

\section{Viitteet}

1 Metadatalla eli metatiedolla tarkoitetaan tässä yhteydessä tietoa jostain sisältöyksiköstä tai tietovarannosta, joka on määrittävää ja kuvailevaa. (Ks. myös Tieteen termipankki: https://tieteentermipankki. fi/wiki/Avoin_tiede:metatieto). Metadatan ideologisista ja poliittisista ulottuvuuksista ks. Dahlgren et al. 2020.

2 Artikkeliin liittyvä tutkimus pohjautuu Suomen Akatemian LibDat: Kohti pidemmälle kehittynyttä lainaus-ja lukemiskulttuuria -konsortion tuloksiin (Launis et al. 2018, 18).

3 https://www.finlit.fi/fi/tutkimus/ edith-suomalaisen-kirjallisuuden-kriittiseteditiot\#.YSo5ml4zZPY ja https://www.finlit. fi/fi/avoin-kalevala\#.YX67Bp5BxPZ. Ks. myös https://www.finlit.fi/fi/tutkimus/tutkimusverkostot/variantti-verkosto/linkkeja\#. YX66nZ5BxPY

4 Digital Literary Stylistics (SIG-DLS) | Official Web page for the ADHO Special Interest Group (SIG) in Digital Literary Stylistics (hypotheses.org)

5 Tällaisiin lähtökohtiin perustuvat monet nykyiset hankkeet, Suomessa esimerkiksi Emil Aaltosen Säätiön rahoittama tutkimushanke Tekstit liikkeessä. Naiskirjailijoiden vastaanotto Suomessa ja Venäjällä 1840-2020 (TeLi, https://tekstitliikkeessa.com/tekstitliikkeessa/), jonka puitteissa tämä katsaus on kirjoitettu. Erilaiset digitaalisen kirjalli- suudentutkimuksen projektit tuovat yhteen kansainvälisiä, monikielisiä tutkijatiimejä, jotka kartoittavat ylirajaista kirjallisuuskenttää tiiviinä yhteistyönä (ks. Parente-Čapková 2017). Elsi Hyttisen Turun yliopiston rahoittama hanke Sallitun halun rajat. 1910-luvun kirjallisuus ja queer sekä Suomen Akatemian rahoittama projekti Figuring Nature in the North. How Contemporary Finnish Literature Makes Sense of Environmental Emergency hyödyntävät laajoja aineistoja ja kansallisbibliografia Fennica-hakuja. Digitaalisiksi voi hankkeissa kutsua aineiston rajaamista ja käsittelyn työkaluja, analyysimenetelmät perustuvat lähilukemiseen.

6 Bergenmarja Golub esittelevät artikkelissaan myös QUEERLIT-projektia ja tietokantaa (ks. https://www.gu.se/en/ research/queerlit-data-base).

7 Kaukolukemalla australialaista 1800luvun lehdistöä Bode on analysoinut sitä transnationaalisen levikin ja vastaanoton paikkana. Hänen tutkimuksensa tarjoavat arvokkaan kontribuution Australian ylirajaiseen kirjallisuushistoriaan ja ne ovat inspiroineet tutkijoita kansainvälisesti. Lehdistöä on analysoitu ja louhittu Suomessakin, kiitos Kansalliskirjaston digitoitujen aineistojen. Niitä ovat käyttäneet mm. kulttuurihistorian hankkeet ja konsortiot (esim. Suomen Akatemian COMHIS, kirjal- 
lisuudentutkimuksesta ks. Dominowska et al. 2019). Lehdistöä hyödyntävät myös kirjallisuutta ja sen laajaa vastaanottoa kartoittavat projektit-TeLin lisäksi esim. Suomen Kulttuurirahaston rahoittama Venäläinen kirjallisuus ja Suomi -projekti. Tärkeänä datarikasteisen historiallisen kirjallisuudentutkimuksen metadataaineistona toimivat kansallisbibliografiat ja kirjastoluettelot, joiden anayysissä ja digitoinnissa on pääosassa bibliografinen datatiede (bibiographic data science, ks. Lahti et al., 2019).

8 Järjestöt ja verkostot tarjoavat aihee- seen liittyville kysymyksille ja ongelmille tilaa työryhmissä ja konferensseissa (Euroopassa esim. EADH, European Association for Digital Humanities tai DARIAH-EU, Digital Research Infrastructure for Arts and Humanities ja sen alla toimiva dariahTeach (https://teach.dariah.eu/), Pohjoismaissa Digital Humaniora i Norden, Suomessa esim. HELDIG eli Helsinki Centre for Digital Humanities-verkosto).

9 Kiitän Elsi Hyttistä ja Kati Launista arvokkaista kommenteista ja huomautuksista.

\section{Kirjallisuus}

Arac, Jonathan 2002. Anglo-Clobalism? New Left Review 16(44).

Ascari, Maurizio 2014. The Dangers of Distant Reading: Reassessing Moretti's Approach to Literary Cenres. Cenre 47(1), DOI: 10.1215/00166928-239234.

Bergenmar, Jenny \& Katariina Leppänen 2017. Gender and Vernaculars in Digital Humanities and World Literature. NORA - Nordic Journal of Feminist and Gender Research 25(4), 232-246. DOI: 10.1080/08038740.2017.1378256.

Bergenmar, Jenny \& Koraljka Colub 2020. Subject Indexing: The Challenge of LGBTQI Literature. DHN, 203-210.

Berry, David M. 2011. The computing turn: thinking about the digital humanities. Culture Machine Vol. 12.

-2012. Introduction: Understanding the Digital Humanities. Understanding Digital Humanities. Ed. David Berry. Basingstoke \& New York: Palgrave Macmillan, 1-20.

Dahlgren, Anna, Karin Hansson, Ramón Reichert \& Amanda Wasielewski 2021. Introduction: The Politics of Metadata. Eds Anna Dahlgren, Karin Hansson, Ramón Reichert, \& Amanda Wasielewski. The Politics of Metadata. Digital Culture and Society 6(2), 5-16. DOI: 10.14361/ dcs-2020-0202.

Doležel, Lubomír \& Richard W. Bailey 1969. Statistics and Style. New York: American Elsevier Publishing Company, Inc.

Dominowska, A., Elsi Hyttinen, Peter Ivanics, Mikko Koho, Ilona Pikkanen \& Risto ]. Turunen 2019. Hiding in Plain Sight: Poetry in Newspapers and How to Approach It. HUMAN IT: TIDSKRIFT FÖR STUDIER AV IT UR ETT HUMANVETENSKAPLICT PERSPEKTIV, 145-171. https://humanit. hb.se/article/view/594.

Elo, Kimmo 2006. Digitaalisen historiantutkimuksen kenttää louhimassa. Teoksessa Digitaalinen humanismi ja historiatieteet. Toim. Kimmo Elo. Turku: Turun Historiallinen yhdistys, 11-35.

Habe, Iven 2020. The audiobook circuit in digital publishing: Voicing the silent revolution. New Media \& Society 22 (3), 409-428. DOI: 10.1177/1461444819863407.

Hall, Cary 2016. Pirate Philosophy: For a Digital Posthumanities. Cambridge, MA: MIT Press. DOI: 10.7551/mitpress/10463.001.0001. 
Hancher, Michael 2016. Re: Search and Close Reading. Teoksessa Debates in the Digital Humanities 2016. Eds Matthew K. Gold \& Lauren F. Klein. Minneapolis: Minnesota University Press, 118-138. DOI: 10.5749/j.ctt1cn6thb.15.

Haverinen, Anna \& Jaakko Suominen 2015. Koodaamisen ja kirjoittamisen vuoropuhelu? - Mitä on digitaalinen humanistinen tutkimus. Ennen ja nyt. Historian tietosanomat 2/2015. https://journal. fi/ennenjanyt/article/view/108634/63637.

Hoover, David L. 2016. Argument, Evidence, and the Limits of Digital Literary Studies. Teoksessa Debates in the Digital Humanities 2016. Eds Matthew K. Gold \& Lauren F. Klein. Minneapolis: Minnesota University Press, 230-250. https://www.jstor.org/stable/10.5749/j.ctt1cn6thb.23.

Jiménez, Ramon 2021 (2019). Shakespeare by the Numbers: What Stylometrics Can and Cannot Tell Us. https://shakespeareoxfordfellowship.org/shakespeare-by-the-numbers-what-stylometricscan-and-cannot-tell-us/.

Jones, Steven E. 2016. Roberto Busa, S. J., and the Emergence of Humanities Computing: The Priest and the Punched Cards. New York: Routledge. DOI: 10.4324/9781315643618.

Katajamäki, Sakari 2020. Pysyviä säkeitä. Ceneettinen invarianssi Kiven "Atalantassa". Joutsen/ Svanen Erikoisjulkaisuja 3: Mansikoita ja mustikoita, 88-106. DOI: 10.33347/jses.100549.

Kim, Dorothy \& Jesse Stommel (eds) 2018. Disrupting Digital Humanities. Punctum Books. DOI: 10.2307/j.ctv19cwdqv.

Kuusela, Hanna 2015. Neroja ja promoottoreita: kirjalliset kuraattorit nykykirjallisuudessa. AvainKirjallisuudentutkimuksen aikakauslehti 12(2), 35-48. DOI: 10.30665/av.74984.

Lahti, Leo, Jani Marjanen, Hege Roivainen \& Mikko Tolonen 2019. Bibliographic Data Science and the History of the Book (c. 1500-1800). Cataloging \& Classification Quarterly, 57(1), 5-23. DOI: 10.1080/01639374.2018.1543747.

Launis, Kati, Eugene Cherny, Mats Neovius, Olli Nurmi \& Mikko Vainio 2018. Mitä naiset lukevat? Vantaan kaupunginkirjaston digitaalisen lainausdatan tulkintaa. Avain-Kirjallisuudentutkimuksen aikakauslehti 4/2018, 5-21. DOI: 10.30665/av.76461.

McPherson, Tara 2015. Why Are the Digital Humanities So White? or Thinking the Histories of Race and Computation. Teoksessa Debates in the Digital Humanities. Ed. Matthew K. Cold. Minnesota Scholarship Online. DOI: 10.5749/minnesota/9780816677948.003.0017.

Moretti, Franco 1998. Atlas of the European Novel 1800-1900. London: Verso.

-2000. Conjectures on World Literature. New Left Review1, 54-68.

-2005. Craphs, Maps, Trees: Abstract Models for a Literary History. London: Verso.

-2013. Distant Reading. London: Verso.

Parente-Čapková, Viola 2017. Naisten kirjoittaman kirjallisuuden ylirajainen vastaanotto. Kohti kirjallisten toimijuuksien historiaa. Avain-Kirjallisuudentutkimuksen aikakauslehti 14(4), 36-49. DOI: 10.30665/av.69305.

—2021 [tulossa]. Matilde Serao in Finlad. Teoksessa Matilde Serao Beyond National Fame: Reframing the Neapolitan Writer's Reception and Network. Eds Ursula Fanning, Katherine Mitchell \& Gabriella Romani. Series "Women and Cender in Italy 1500-1900". Paris: Classique Garnier.

Pettersson, Bo 2016. Fjärrläsningochnärläsning, stordataochsmådata. Historiaiendigitalvärld, (version 2.0 av det webbaserade bokprojektet). Red. Jessica Parland-von Essen \& Kenneth Nyberg. https:// digihist.se/hdv2/fordjupningar/farrlasning-och-narlasning-stordata-och-smadata/\#fn1.

Piippo, Laura \& Hanna-Riikka Roine 2020. Kirjallisuudesta ja sen lukijoista digitaalisissa ympäristöissä. niin \& näin 3, 29-34.

Pynsent, Robert 1973. Julius Zeyer: The Path to Decadence. The Hague-Paris: Mouton. DOI: $10.1515 / 9783112316375$.

Roine, Hanna-Riikka \& Laura Piippo 2021. Kirjallisuus ja sen tutkimus digitaalisissa ympäristöissä. Avain-Kirjallisuudentutkimuksen aikakauslehti 18(2), 6-27. DOI: 10.30665/av.102654. 
Sanz, Amelia 2013. Digital Humanities or Hypercolonial Studies? RICT, Responsible Innovation, Ethical Issues 2013. https://core.ac.uk/download/pdf/163094852.pdf.

-2017. Digital Literatures Circulation: Testing Post-Bourdieu Theories. Neohelicon, April, 1-11.

Spivak, Gayatri Chakravorty 2003. Death of a Discipline. New York: Columbia University Press.

Suominen, Jaakko \& Anna Sivula 2016. Digisyntyisten ilmiöiden historiantutkimus. Teoksessa Digitaalinen humanismi ja historiatieteet. Toim. Kimmo Elo. Turun historiallinen yhdistys ry, 96-130.

Tolonen, Mikko 2016. Paradigm shift? How are digital humanities changing the humanities? Esitelmä paneelikeskustelussa. $1^{\text {st }}$ Conference of DHN (Digital Humanities in the Nordic countries/ Digital Humaniora i Norden), Oslo, 15-17 March, 2016.

-2017. Digitaalinen humanismi ja digitalia. Teoksessa Digitaalinen tieto haltuun. Ratkaisuja digitaalisten aineistojen hallintaan ja käyttöön. Toim. Miia Kosonen. Mikkeli: Kaakkoissuomen ammattikorkeakoulu. http://urn.fi/URN:ISBN:978-952-344-020-3.

Tolonen, Mikko \& Leo Lahti 2018. Digitaaliset ihmistieteet ("Digital Humanities") ja historiantutkimus. Teoksessa Menneisyyden rakentajat: teoriat historiantutkimuksessa. Toim. Matti O. Hannikainen, Mirkka Danielsbacka \& Tuomas Tepora. Helsinki: Gaudeamus, 235-258. https:// helda.helsinki.fi/bitstream/handle/10138/309808/Tolonen_M_Lahti_L_Digitaaliset_ihmistieteet_Digital_Humanities_ja_historiantutkimus.pdf?sequence $=1$.

Underwood, Ted 2017. A Genealogy of Distand Reading. Digital Humanities Quarterly 11(2). http://www.digitalhumanities.org/dhq/vol/11/2/000317/000317.html.

Vairinen, Virpi 2021. Kansainvälinen suomalainen elektronisen kirjallisuuden kenttä. Avain - Kirjallisuudentutkimuksen aikakauslenhti 18(2), 102-105. DOI: 10.30665/av.105339.

Wernimont, Jennifer 2013. Whence Feminism? Assessing Feminist Interventions in Digital Literary Archives. Digital Humanities Quarterly 7(1). URL: http://www.digitalhumanities.org/dhq/ $\mathrm{vol} / 7 / 1 / 000156 / 000156 . \mathrm{html}$. 